Revista Destaques Acadêmicos, Lajeado, v. 11, n. 2, 2019. ISSN 2176-3070

DOI: http://dx.doi.org/10.22410/issn.2176-3070.v11i2a2019.2193

http://www.univates.br/revistas

\title{
A INSERÇÃO DO PÚBLICO FEMININO NO MARKETING ESPORTIVO
}

\author{
Gabriella Matte Andreis ${ }^{1}$, Claudia Lehnemann Tannhauser ${ }^{2}$, \\ Uiliam Hahn Biegelmeyer ${ }^{3}$, Maria Emília Camargo ${ }^{4}$, \\ Flávia Camargo Bernardi ${ }^{5}$, Gabriela Zanadrea ${ }^{6}$
}

Resumo: Este estudo analisou as motivações que levam as mulheres integrantes do Núcleo de Mulheres Gremistas a consumir, participar e acompanhar o futebol, elencando os principais fatores que influenciam neste comportamento. Para atingir esse objetivo, foram realizadas duas etapas de pesquisa: a primeira uma pesquisa bibliográfica com o propósito de entender e fundamentar o presente estudo, e após, a realização de um grupo focal com 13 participantes do Núcleo de Mulheres Gremistas. Essa técnica consiste em instigar uma discussão e um debate a cerca do tema proposto. Com o intuito de entender os principais estímulos e impulsos que levam ao interesse e consumo do produto futebol. Para tanto, foi elaborado um roteiro de entrevista semiestruturado, composto com 14 perguntas abertas. Os resultados finais, com base na amostra selecionada, apontam a família, fanatismo, paixão clubística e gosto pelo esporte como os fatores determinantes desta preferência e interesse.

Palavras-chave: Marketing Esportivo; Comportamento do Consumidor; Mulheres; Núcleo de Mulheres Gremistas; Futebol.

\section{INTRODUÇÃO}

A entrada da mulher no ambiente esportivo ainda não é absoluta, causando em alguns lugares estranhamento e algumas atitudes preconceituosas.

1 Bacharel em Administração.

2 Doutora em Ciências da Saúde.

3 Doutor em Administração.

4 Doutora em Engenharia de Produção.

5 Mestra em Administração.

6 Doutora em Administração. 
Segundo Dunning (1992, p. 390), o "desporto, tradicionalmente é uma das mais importantes áreas reservadas masculinas, e por este motivo de potencial e importância para o funcionamento de estruturas patriarcais".

De acordo com Limeira (2008), nas últimas décadas, as mulheres passaram por diversas mudanças comportamentais ligadas a costumes, valores e estilos de vida. O modo como elas veem o mundo, enfrentam os desafios e buscam os seus sonhos mudaram e continuam mudando.

A inserção do público feminino no futebol não é um fenômeno atual. A presença das mulheres nos estádios nasceu no início do século $X X$, quando elas iam aos jogos e eventos trajando vestidos, luvas e chapéus (GOELLNE, 2014). Em função de quentes temperaturas, algumas dessas moças tiravam as luvas e torciam. Essa atitude originou o termo "torcedoras", palavra que foi apropriada pelo vocabulário futebolístico brasileiro (GOELLNE, 2014). Segundo Costa (2007, p. 7), "o futebol, assim como outras modalidades esportivas, proporcionou à mulher uma das raras oportunidades de exposição e entrada nos espaços públicos".

O aumento da presença da mulher no âmbito esportivo fica evidenciado na existência de um grupo formado por mulheres apreciadoras e fanáticas pelo futebol. Esse é o caso do Núcleo de Mulheres Gremistas. Esse núcleo foi fundado no ano 2004, através da união de diversas torcedoras que já se conheciam por frequentarem as arquibancadas sociais do Estádio Olímpico. O objetivo desse núcleo é reunir as torcedoras que desejam promover atividades com o intuito de apoiar e valorizar o Grêmio e, principalmente, o futebol. De acordo com informações do site oficial, o Núcleo de Mulheres Gremistas iniciou suas atividades com a participação de 20 mulheres. Atualmente, o movimento conta com mais de 2.000 mulheres cadastradas através do site, sendo que aproximadamente 60 mulheres participam mensalmente de todas as atividades.

Desta forma, este estudo tem como questão de pesquisa: "Quais são os fatores que influenciam o consumo do produto futebol pelas integrantes do Núcleo de Mulheres Gremistas?". O objetivo geral é analisar as motivações que levam essas mulheres a consumir, participar e acompanhar o futebol, tendo como objetivo secundário identificar quais são as influências sofridas por elas neste contexto.

Tendo em vista o cenário atual de globalização e concorrência, entender o comportamento do consumidor, conhecer o perfil do cliente é essencial para atingir o sucesso nos negócios. Solomon (2011, p. 33), afirma que "o campo do comportamento do consumidor abrange uma ampla área: é o estudo dos processos envolvidos quando indivíduos ou grupos selecionam, compram, usam ou descartam produtos, serviços, ideias ou experiências para satisfazer necessidades e desejos". 


\section{REFERENCIAL TEÓRICO}

\subsection{A mulher na sociedade}

Pereira (2006), relata que o grande desejo da contemporaneidade é a igualdade de direitos entre homens e mulheres. Porém, hoje existem ainda algumas discriminações de gêneros, que resultam na inferioridade da mulher em relação ao homem. O mesmo autor relata que no ano de 1998 foi realizada na China a Conferência Mundial de Mulheres, que buscava discutir as violações dos direitos e as desigualdades impostas pela sociedade. Segundo Martins et al. (2015), historicamente a mulher foi predestinada a ser minimizada diante da figura masculina, jamais vista em uma ótica igualitária ao homem.

Entretanto, números mostram a evolução da mulher na sociedade. Estudos realizados pelo Instituto Brasileiro de Geografia e Estatística (IBGE) no ano de 2012 apresentam resultados que relatam o fortalecimento da participação feminina no mercado trabalho, devido a superioridade no nível de escolaridade. Hoje, as mulheres representam $51 \%$ dos mais de 200 milhões de brasileiros. Nos últimos 10 anos, a renda feminina aumentou de $\mathrm{R} \$ 600$ bilhões para $R \$ 1,1$ trilhões. Segundo Somoggi (2016), nas últimas décadas nada foi mais significativo que a importância da mulher em termos sociais e econômicos. O mesmo autor relata que o papel da mulher na sociedade é fundamental para evolução do país.

\subsection{Marketing: conceitos e definições}

O marketing é uma ferramenta utilizada por muitas empresas e o seu papel é, segundo Cardia (2014, p. 2), "descobrir, produzir, criar, distribuir e promover bens e serviços que venham a ser desejados pelas pessoas ou grupo de pessoas no momento certo, no lugar certo, ao preço justo". Siqueira (2014) define o marketing como uma filosofia que estuda as implicações da relação entre as corporações e o mercado. Porém, o mercado de hoje é considerado incerto e instável, o que na maioria das vezes impossibilita a construção de um cenário. Com isso, a ferramenta de marketing é versátil, como Cardia (2014, p. 2) destaca: "o marketing de ontem não é o mesmo de hoje, que é diferente do de amanhã".

Segundo Rocha (1999, p. 15), “o marketing é uma função gerencial que busca ajustar a oferta da organização à demanda específica do mercado, utilizando como ferramentas, um conjunto de princípios e técnicas".

Para melhor entendimento do conceito de marketing, pode-se afirmar que este se trata de um "processo de desenvolvimento, produção, precificação, promoção e distribuição de produtos e serviços que satisfaçam às necessidades das pessoas das organizações" (VAVRA, 1993, p. 168). 
O marketing pode ser aplicado a diferentes tipos de produtos e serviços. Uma dessas linhas é o marketing voltado aos esportes e aos produtos e serviços a ele relacionados. Nesse estudo, é imprescindível buscar o maior entendimento de como se desenvolvem esses conceitos dentro do futebol.

\subsubsection{Marketing Esportivo}

Com a finalidade de descrever as técnicas de marketing utilizadas dentro do esporte, no ano de 1978 surgiu o Marketing Esportivo. A partir de então, os estudos na área cresceram a ponto de se tornar uma área específica de pesquisa, acompanhando o mercado e o volume de movimentação financeira gerada pelo esporte em todo o mundo (PITTS; STOTLAR, 2002). Dias e Costa (2009) ressaltam que o marketing só começou a ganhar uma proporção maior no mundo do esporte a partir dos grandes eventos esportivos, com o advento das transmissões esportivas pela televisão, como Olimpíadas, Copa do Mundo de Futebol e Corridas de Fórmula 1.

Os autores consideram que essa é a principal função de um negócio esportivo atualmente, devido ao grande desenvolvimento dessa indústria. Shank (2002, p. 2), define Marketing Esportivo como "a aplicação específica dos princípios e processos de marketing aos produtos esportivos e ao marketing de produtos não-esportivos por meio da associação com o esporte".

O Marketing Esportivo desenvolve produtos e serviços direcionados ao consumidor de esporte. A partir dessa definição, entende-se como consumidor do esporte aquele que tem diversos tipos de envolvimento com este, como praticar, assistir, ouvir, ler, colecionar ou escrever sobre o assunto. O consumo esportivo é uma atividade comercial em crescimento considerável nos últimos anos. O esporte tem a capacidade de atingir pessoas de todas as idades, culturas e classes sociais (MORGAN; SUMMERS, 2008).

Dubois (1998, p. 20) afirma que "compreender o consumidor é uma necessidade vital para as empresas". Sem conhecer o que o consumidor anseia, necessita ou tem como expectativa, torna-se difícil tomar decisões. Além disso, entender como, quando, porque, onde e com que frequência eles adquirem e usam o que compram para que, então, possa criar produtos ou serviços que irão satisfazê-los de maneira completa (SAMARA E MORSCH, 2005).

$\mathrm{O}$ estudo do comportamento do consumidor surge para fornecer essas respostas, tornando os profissionais de marketing capazes de prever a "probabilidade de os consumidores reagirem a vários sinais informacionais e ambientais" (SCHIFFMAN E KANUK, 2000, p. 6).

\subsection{Comportamento do consumidor}

De acordo com Samara e Morsch (2005, p. 3), "o comportamento do consumidor se caracteriza como processo: um conjunto de estágios que 
envolvem a seleção, a compra, o uso ou a disposição de produtos, ideias ou experiências para satisfazer necessidades e desejos".

Blackwell, Miniard e Engel (2011), descrevem o comportamento do consumidor como as atividades nas quais as pessoas se ocupam para realizar a compra e consumo de produtos ou serviços. Simplificadamente, os autores definem como o estudo de por que as pessoas compram. Schiffman e Kanuk (2000) explicam que o estudo do comportamento do consumidor tem como objetivo identificar a maneira como os indivíduos tomam as suas decisões para gastar seus recursos monetários e não monetários (o tempo, o dinheiro e os esforços).

Garcia et al. (2010) afirmam que o comportamento do consumidor deve ser estudado por diversas áreas de conhecimento, como a Psicologia, a Sociologia, a Antropologia, a Economia e a Administração, inclusive pela área de marketing, pois o comportamento do consumidor desperta interesse pela sua complexidade e importância. Portela (2008) complementa que o profissional de marketing deve saber de onde surgiu determinado impulso e o que motivou os consumidores, com o objetivo atender essas motivações e suprir as necessidades.

Schiffman e Kanuk (2000) compreendem que o indivíduo, como consumidor, sofre influências psicológicas, pessoais, sociais, econômicas e culturais. As preferências, os gostos, e as compras são motivadas por alguns fatores e esses são determinantes na compra (KOTLER E ARMSTRONG, 2007). Kotler (2006) ressalta que existem quatro fatores que influenciam no comportamento do consumidor, são eles: fatores culturais, sociais, pessoais e psicológicos.

\subsubsection{Comportamento da Consumidora}

Conforme Popcorn e Marigold (2000), mulheres compram ou influenciam na obtenção de $80 \%$ dos produtos de consumo. As mulheres desejam marcas que tenham significados, marcas que entendam as suas necessidades, seus valores, seus padrões e seus sonhos.

De acordo com Underhill (1999), o ato de comprar ainda é considerado uma atividade feminina. Os autores Popcorn e Marigold (2000) relatam que as mulheres são mais intuitivas que os homens, conseguem as informações de forma rápida, porém não essencialmente na tomada de decisão, as mulheres são mais rigorosas na estrutura e nos detalhes.

Underhill (1999) complementa que as mulheres são mais resignadas e questionadoras, sentindo-se à vontade no seu espaço de compra. $\mathrm{O}$ autor afirma também que as compras são e sempre serão de domínio feminino, pois o ato de comprar é um costume feminino. Ainda na visão de Underhill (1999), as mulheres caem em devaneio ao sair às compras, imaginam os prós e os contras. 
Giglio (1996) destaca que a mulher passa a contribuir na compra de produtos que antes não participava devido à ascensão no mercado de trabalho. O orçamento doméstico também ganha papel respeitável e muda alguns pontos de comportamento. Na visão de Underhill (1999), existem duas explicações sobre o heroísmo feminino em relação às compras: o aspecto biológico, pois desde os primeiros tempos o papel da mulher naturalmente era a protetora do lar. O segundo aspecto é o cultural, pois pré-historicamente as mulheres não participavam do comércio.

Segundo Barlleta (2003), o complemento final para que as mulheres decidam em relação à compra do produto ou serviço se dá através da compreensão total das informações, demonstrando uma relação de lealdade. Blackwell, Miniard e Engel (2011) afirmam que os papéis femininos são de grande importância hoje para os profissionais de marketing. Esses estão especialmente preocupados com os papéis de gênero na família e nas suas posições como agente de compra.

\subsubsection{Comportamento do consumidor esportivo}

Siqueira (2014) relata que existem alguns fatores que levam os indivíduos a consumirem esporte, seja em forma de informação, de produtos ou de serviços. São eles: elevação da autoestima, dissociação do dia a dia, entretenimento, interesse econômico, valor estético, inclusão social, união social.

Conforme Pitts e Stotlar (2002), o consumidor esportivo pode ser alocado em três tipos de segmentos: (a) prática esportiva - que é oferecida ao consumidor como produto de participação e/ou entretenimento; (b) produtos esportivos - produtos e serviços, como equipamentos esportivos e serviços médicos, ofertados aos consumidores para a prática de esportes; e (c) promoção esportiva - produtos e serviços que são ofertados para promover o esporte, incluindo eventos, brindes e patrocínios, por exemplo.

Rein, Kotler e Shields (2008) afirmam que a crescente concorrência e esportes novos ou emergentes cooperam para fragmentar o mercado esportivo, dificultando a atuação das organizações do setor.

Os autores atribuem as seguintes características a esse mercado dinâmico: (a) ambiente altamente competitivo; (b) torcedores com expectativas elevadas; (c) conflito entre o conceito de esporte como negócio e como competição; (d) surgimento de novas tecnologias; (e) interesses cada vez mais individuais dos consumidores; (f) mudanças na estrutura e no comportamento das famílias; e (g) falta de tempo dos consumidores.

Rein, Kotler e Shields (2008) relatam ainda que existem conectores fundamentais que ligam os torcedores aos esportes. O primeiro é o astro, que pode envolver um jogador, equipe, torneio, estádio ou outro elemento que atraia torcedores. A outra conexão é estabelecida pelo local, que se relaciona com a necessidade de interação comunitária e de filiação dos torcedores. $\mathrm{O}$ 
último grupo de conectores são os de busca, compostos por três formas de conexão: experiências indiretas; incerteza, que considera a imprevisibilidade do esporte; e utopia, que considera as experiências esportivas que representam o passado do torcedor.

Eles também apontam os seguintes canais de acesso para os torcedores: (a) prática esportiva; (b) experiência no local; (c) mídia; (d) divulgação boca a boca; e (e) mentor - indivíduo interessado em envolver outras pessoas no esporte.

\section{$2.4 \mathrm{O}$ esporte futebol}

O esporte e a sua indústria têm crescido muito nos últimos anos. Conforme Siqueira (2014), o esporte como negócio movimentará cerca de 1,5 trilhões de dólares na próxima década, seja em patrocínios, em direitos de transmissão e vendas de produtos ou ingressos para os eventos. Tendo em vista esses fatos, é possível destacar o futebol, que hoje é considerado um fenômeno mundial e apresenta um mercado potencial e valioso, tornando-o atraente e lucrativo para grandes marcas e entidades ao redor do mundo.

Segundo Siqueira (2014), o futebol atrai diversos mercados, devido à visibilidade que o mesmo proporciona, atingindo diversas mídias e públicos diferentes.

De acordo com Zenone (2014), os clubes de futebol aplicam estratégias que têm como objetivos aumentar as receitas e tornar a marca um símbolo reconhecido. E quando se trata de diferentes gêneros, é importante observar o aumento do público feminino frequentando e consumindo o produto futebol.

\subsection{Inserção do público feminino no futebol}

Segundo Campos e Silva (2009), o futebol está presente no cotidiano de homens e mulheres de todas as idades, através do consumo de mercadorias, de lazer e de entretenimento. De acordo com Campos e Silva (2009), o público feminino encontra dificuldades de legitimar o seu torcer, com base na premissa de que mulher não entende de futebol e que estádio não é local de mulher.

Todavia, desde a antiguidade as mulheres eram bem vistas, pois davam um ar elegante, belo e tranquilo ao esporte (CAMPOS E SILVA, 2009). Nos dias de hoje, a modernização das arenas e o aumento de seguranças e transformação do ambiente menos hostil tornam a atmosfera de convivência melhor, chamando o público feminino para dentro dos estádios (CARVALHO, 2016). Entretanto, de acordo com Felicio (2009), não há como negar que a mulher ainda é um elemento pouco integrado ao universo futebolístico. $\mathrm{O}$ mesmo autor ainda afirma que: "o incentivo e participação da torcida feminina nos estádios de futebol ainda apresenta um caráter tímido" (FELICIO, 2009, p. 29). 
O aumento da participação feminina na sociedade moderna, como ressalta Costa (2007), rompe paradigmas do predomínio masculino e retira a ideia de que a mulher e o futebol atuam em campos opostos. Um fato que demonstra a inserção da mulher no futebol brasileiro é a expansão do Mix de Marketing. Os clubes brasileiros começaram a sentir a demanda por produtos específicos destinados ao público feminino (CARVALHO, 2016).

Outro fator interessante a ressaltar é o grande número de torcidas organizadas femininas dos Clubes do Futebol Brasileiro. Podem-se citar como alguns exemplos: Pelotão Feminino (RJ ם Flamengo), Camisa 12 (RJ ם Vasco da Gama), Mulheraço (RJ ם Volta Redonda), Gatas da Fiel (Pará u Paysandu), Torcida Feminina Guerreiras Alvinegras (Botafogo - RJ) e Torcedora Tricolor (Grêmio - RS). Além das torcidas, as mulheres se reúnem através das mídias sociais, seguindo páginas de conteúdo futebolístico destinadas para o público feminino (FELICIO, 2009).

Uma pesquisa realizada no ano de 2013, pela Pluri Consultoria, demostrou que em média $50 \%$ dos torcedores de um clube de futebol são do sexo feminino, totalizando 98 milhões de torcedoras espalhadas por todo o território brasileiro.

O aumento da participação da mulher no território do futebol é um acontecimento relativamente recente, tendo poucos referenciais teóricos disponíveis. Com isso, torna-se de grande valia a elaboração de um estudo que visa identificar e analisar os fatores que influenciam o comportamento de compra do público feminino pelo produto futebol. Para tanto, fez-se necessário realizar uma pesquisa de campo que possibilitou o confronto entre os dados coletados e a pesquisa bibliográfica.

\section{MÉTODO DE PESQUISA}

Para o desenvolvimento deste artigo, foi realizada uma pesquisa qualitativa. Segundo Malhotra (2006), a pesquisa qualitativa é uma metodologia que possibilita a percepção e compreensão do problema em questão, baseado em pequenas amostras. Flick (2009, p. 37), define: “a pesquisa qualitativa dirige-se a análise de casos concretos em suas peculiaridades locais e temporais, partindo das expressões e atividades das pessoas em seus contextos locais".

Quanto ao objetivo de pesquisa, Malhotra (2006) define que a pesquisa exploratória tem por objetivo fazer uma busca na situação escolhida para maior compreensão da mesma, desvendando características, comportamentos, atitudes, percepções e as motivações da amostra selecionada. Em razão disso, a opção foi realizar uma pesquisa exploratória, visto que o assunto é o comportamento das consumidoras do Núcleo de Mulheres Gremistas. Para (2012), esse tipo de pesquisa é utilizado com alguns dos seguintes propósitos: (a) familiarizar e elevar o conhecimento e a compreensão de um problema de pesquisa em perspectiva, (b) ajudar no desenvolvimento ou na criação 
de questões de pesquisa relevantes para o objetivo pretendido, (c) ajudar no delineamento do projeto final da pesquisa.

No primeiro estágio da metodologia, foi desenvolvida uma pesquisa bibliográfica, que teve como intuito de entender e fundamentar o referente estudo.

Adicionalmente, o outro método utilizado para desenvolvimento desse estudo foi a entrevista de Grupo Focal, que, segundo Malhotra (2006), caracteriza-se por uma técnica de grupo, realizada de maneira não-estruturada. De acordo com Mc Daniel (2003), essa entrevista tem como propósito compreender e revelar as percepções dos participantes sobre os assuntos em discussão. Essa técnica foi escolhida com o objetivo de analisar o comportamento e as influências das participantes do Núcleo de Mulheres Gremistas em relação ao futebol.

\subsection{Amostragem}

Malhotra (2006, p. 320) define amostra como: "um subgrupo dos elementos da população selecionado para participação no estudo". O mesmo autor relata que o processo de elaboração da amostra inclui cinco estágios, que são: definição da população alvo, determinação da composição da amostra, seleção da(s) técnica(s) de amostragem, determinação do tamanho da amostra e, por fim, a execução do processo de amostragem.

Nesta pesquisa, a população alvo foi composta por mulheres membros do Núcleo de Mulheres Gremistas, da faixa etária de 25 a 75 anos, residentes no estado do Rio Grande do Sul, apreciadoras do produto Futebol.

Diante do exposto, o presente estudo utilizou como técnica a amostragem não probabilística. $\mathrm{O}$ fato de ser torcedora, frequentadora, apreciadora do produto futebol e integrante do Núcleo de Mulheres Gremistas, foi o critério de composição da amostra intencional, realizada por julgamento.

A definição do tamanho da amostra levou em consideração a natureza da pesquisa e técnica escolhida para coleta de dados do caso em estudo. Sendo assim, optou-se por uma amostra pequena, em relação ao número de participantes cadastradas no Núcleo de Mulheres Gremistas. Também foi limitador da escolha da amostra o fato destas mulheres terem uma participação frequente nas reuniões mensais pré-definidas por este grupo.

\subsection{Instrumento de coleta de dados}

Mattar (2012, p. 108) define como instrumento de coleta de dados o "documento através do qual as perguntas e questões serão respondidas aos respondentes e onde são registradas as respostas e os dados obtidos". O instrumento escolhido para a coleta de dados durante o grupo focal foi o de entrevista semiestruturada. Malhotra (2006) afirma que o objetivo desse tipo 
de instrumento é obter informações dos entrevistados, sobre determinado assunto ou problema. Segundo Limeira (2008), é uma técnica semiestruturada que contém uma lista de perguntas, escritas ou orais, abertas ou fechadas. Marconi (2002) acrescenta que essa técnica é utilizada com o intuito de dar ao entrevistado uma liberdade de resposta.

O roteiro da entrevista semiestruturada foi respondido na data do Grupo Focal, com a presença do pesquisador e do observador. As perguntas foram de caráter aberto, pois as mesmas têm intenção de proporcionar ao pesquisador a observação e interpretação da visão dos interrogados, porque os mesmos respondem livremente o que pensam sobre o assunto.

\subsection{O Grupo Focal}

O Grupo Focal realizado com as integrantes do Núcleo de Mulheres Gremistas ocorreu na Hamburgueria 1983, localizada no Shopping Praia de Belas, na cidade de Porto Alegre. Contou com a participação de 13 mulheres integrantes do núcleo.

Para a execução desse método, foi necessária a utilização de recursos de filmagem e gravação de áudio. A discussão foi gravada por dois gravadores de áudio, e também filmada com uma, câmera portátil que capta fotos e vídeos por meio de lentes grande-angulares. Foi utilizado um facilitador responsável por conduzir a filmagem e fazer algumas anotações das emoções demonstradas pelas participantes ao responder determinada pergunta.

Para a condução do Grupo Focal, foi elaborada uma dinâmica, dividida em quatro etapas:1. Preparação do ambiente: momento em que foi apresentada a problemática do trabalho e explicada a definição da ferramenta utilizada para a coleta de dados; 2.Apresentação das participantes: com o objetivo de conhecer o perfil das integrantes do grupo, foi proposta uma apresentação individual. Identificando o nome, idade, estado civil, escolaridade e profissão; 3. Realização da entrevista/debate/discussão coletiva: nesta etapa, utilizou-se o roteiro de entrevista semiestruturada; 4.Agradecimento: Para finalizar, foi entregue para todas as integrantes um alfajor personalizado, escrito Núcleo de Mulheres Gremistas, como forma de agradecimento da participação delas nessa fase do estudo.

\subsection{Análise dos dados}

Para a interpretação dos dados advindos do Grupo Focal, realizado com 13 participantes do Núcleo de Mulheres Gremistas, utilizou-se a técnica de análise de conteúdo. De acordo com Bardin (2009), a análise de conteúdo consiste no conjunto de procedimentos e técnicas de investigação, que tem por finalidade a descrição objetiva, sistemática e qualitativa do material. Neste sentido, na primeira etapa da análise, os dados passaram por um processo de codificação que, segundo Bardin (2009), é a transformação dos dados brutos, a 
agregação que permite a obtenção de conteúdos significativos. Por conseguinte, utilizou-se a categorização que, para Bardin (2009), é o processo de classificação dos dados através de um critério de agrupamento predefinido. Optou-se pelo uso de um critério de caráter semântico, que resultou na criação das seguintes categorias: o futebol, a presença feminina e influências no cotidiano.

\section{APRESENTAÇÃO E ANÁLISE DOS RESULTADOS}

\subsection{O futebol - a paixão de todas as idades e sexos}

Essa categoria é composta por os seguintes códigos: família, gostos e preferências, consumo e o fanatismo.

$\mathrm{Na}$ análise dos dados, constatou-se que um dos fatores que impulsionam o público feminino a consumir o produto futebol é principalmente a influência familiar. Rein, Kotler e Shields (2008) relatam que o esporte é um conector que incentiva a interação social, e a família, pois pode ser considerado um fator de união. Durante o grupo, várias participantes contaram com muita emoção lembranças da infância, principalmente ligadas a figura do pai ou do avô que, fanáticos por futebol, incentivavam a família a acompanhar as partidas e torcer pelo time do coração. Uma das participantes relata: "Meus pais sempre foram muito ativos, torcedores apaixonados pelo Grêmio, desde criança ia ao Olímpico com eles".

Outro fator predominante é a existência de um atleta no âmbito familiar, que desperta o gosto e a paixão pelo futebol. Segundo Kotler (2006), existem quatro fatores que influenciam no comportamento do consumidor, são eles: fatores culturais, sociais, pessoais e psicológicos.

Foi possível também observar que os filhos contagiam as mães, motivados em um primeiro momento pela necessidade de companhia e segurança nos jogos. Descreve uma das integrantes: "precisava acompanhar meu filho em uma torcida organizada, antes assistia os jogos esporadicamente, mas a partir daí cresceu uma vontade louca de acompanhar o futebol".

Foi abordado como as famílias encaram o gosto e preferência dessas mulheres pelo futebol. Laura, 52 anos, comenta: "me apoiam e em muitas ações participam juntos, meu marido é louco por futebol e também é gremista". Outra integrante do grupo adiciona: "sempre fui muito autônoma nas minhas decisões e minha família sempre respeitou isso".

Outro fator discutido foi o gosto pelo esporte, várias comentaram sobre o interesse por este tema desde a infância. "Sempre, desde criança gostei de esportes. Quando estudante, participava de campeonatos de vôlei e futebol. Inclusive depois de adulta participei de campeonatos de futebol por uma empresa onde trabalhei. Atualmente, eu torço pelo futebol e vôlei. Outra ressalta: "É um hobby, onde encontro muitos amigos para me divertir. Sempre gostei de esporte de equipes, pois pratiquei esportes em toda minha juventude". 
Existe no grupo uma integrante que é atleta e mesmo sendo de outro estado simpatizou com o time e hoje representa o clube em várias localidades dentro e fora do país. A paixão pelo futebol culminou várias vezes durante o desenvolvimento do grupo: "Acompanho o futebol e o Grêmio há 62 anos porque considero um dos esportes mais emocionantes; claro que a isto se soma a minha paixão pelo clube, decorrente de tantas alegrias que o Grêmio já me deu".

Os produtos consumidos são variados: camisetas, acessórios, enfeites de decoração, roupas. Maria, 49 anos, coleciona todos os produtos personalizados do clube e disse: "Me faz bem, tenho um pequeno memorial do Grêmio em minha casa, é meu orgulho".

Os consumidores do esporte são elementos fundamentais para aqueles que gerem o esporte como negócio. Siqueira (2014) relata que existem alguns fatores que levam os indivíduos a consumirem esporte, seja em forma de informação, de produtos ou de serviços. São eles: elevação da autoestima, dissociação do dia a dia, entretenimento, interesse econômico, valor estético, inclusão social e a união social.

Conforme Popcorn e Marigold (2000), mulheres compram ou influenciam na obtenção de $80 \%$ dos produtos de consumo. As mulheres desejam marcas que tenham significados, marcas que entendam as suas necessidades, seus valores, seus padrões e seus sonhos.

A maioria delas é sócia do clube e tem o hábito de frequentar os jogos, participando ativamente das partidas de futebol. Das 13 participantes do grupo focal, dez são sócias do clube, e vão a todos os jogos. E três não são sócias, por motivos financeiros ou por morar fora de Porto Alegre. Muitas relatam a importância de serem sócias, seja por comodidade para assistir aos jogos, orgulho ou apenas para ajudar o clube. Fernanda, 45 anos afirma:

Sim, sou sócia com muito orgulho. Há muitos anos, porque participo ativamente das atividades do clube indo aos jogos e eventos e também porque é uma forma de ajudar meu clube a crescer cada vez mais. Os sócios são a verdadeira razão de ser do clube.

Segundo Campos e Silva (2009), o futebol está presente no cotidiano de homens e mulheres de todas as idades, através do consumo de mercadorias, de lazer e de entretenimento.

\subsection{A presença feminina no âmbito esportivo}

Os códigos que compõem essa categoria são: preconceitos, presença nos estádios e a participação econômica.

O aumento da presença do público feminino no futebol tem causado estranhamentos entre os grupos. De acordo com Campos e Silva (2009), o 
público feminino encontra dificuldades de legitimar o seu torcer, com base na premissa de que mulher não entende de futebol e que estádio não é local de mulher. No entanto, elas comentaram sobre o aumento do público feminino nos estádios. Citam que hoje essa atuação é mais tranquila e se sentem à vontade. $\mathrm{O}$ aumento da participação feminina na sociedade moderna, como ressalta Costa (2007), rompe paradigmas do predomínio masculino e retira a ideia de que a mulher e o futebol atuam em campos opostos. Nos dias de hoje, a modernização das arenas e o aumento de seguranças e a transformação do ambiente menos hostil tornam a atmosfera de convivência melhor, chamando assim o público feminino para dentro dos estádios (CARVALHO, 2016).

Segundo Felicio (2009), não há como negar que a mulher ainda é um elemento pouco integrado ao universo futebolístico. $\mathrm{O}$ mesmo autor afirma que: "o incentivo e participação da torcida feminina nos estádios de futebol ainda apresenta um caráter tímido" (FELICIO, 2009, p. 29). O exemplo da liderança feminina influência muito e está diretamente ligada à auto estima destas líderes e a confiança que transmitem para suas lideradas a fim de que ambas alcancem o sucesso( CUPINI, et al,2017).

Outro tópico abordado pelas participantes foi a dificuldade de participar do futebol devido às condições monetárias e que somente após uma estabilidade no mercado de trabalho e independência, é que foi possível desenvolver e acompanhar as ações e os jogos. Lembra Popcorn e Marigold (2000), que a entrada da mulher no mercado de trabalho é extremamente importante para $o$ marketing. A autora ressalta que as mulheres conquistaram finalmente $o$ direito de concorrer a quaisquer papéis que quiserem, mas não podem abrir mão de alguns deles, assim os papéis continuam acumulando-se.

Giglio (1996) destaca que a mulher passa a contribuir na compra de produtos que antes não participava devido à ascensão no mercado de trabalho, e o orçamento doméstico também ganha papel respeitável e muda alguns pontos de comportamento.

\subsection{Influências no cotidiano}

Essa categoria foi desenvolvida através desses critérios: Humor, paixão clubística e o Núcleo de Mulheres Gremistas.

O humor dessas mulheres também é acometido pela vitória ou derrota do time. Muitas mencionam que ficam irritadas, caladas e até um pouco tristes e com raiva se o resultado não for positivo. "Atualmente, fico triste somente no dia, depois não leio e procuro não ver notícias". Outra participante do Grupo Focal, contou que já foi mais fanática, que ficava doente, que tinha que tomar remédios para dormir ou calmantes quando o Grêmio perdia.

Foi observada uma grande paixão pelo esporte, o apreço e amor pelo clube foram enaltecidos durante toda a realização do grupo. Isso ficou nítido quando elas comentaram com risos o fato de terem assistido outras 
modalidades esportivas nas Olimpíadas Rio 2016 apenas com intuito de ver quantas pessoas estavam com a camiseta do Grêmio nas arquibancadas. Hoje, elas ficam orgulhosas de perceber a visibilidade que o clube tem fora do estado do Rio Grande do Sul.

A participação no Núcleo de Mulheres Gremistas representa para muitas das participantes uma diversão, companhia, atividade para a rotina e, acima de tudo, muita identificação e amizade. $\mathrm{O}$ fato de elas terem um grupo de amigas para irem aos jogos possibilita uma concentração apenas de mulheres antes e depois dos jogos, e isso motiva-as a continuarem assíduas no núcleo.

Carmen, 68 anos, uma das fundadoras do Núcleo de Mulheres Gremista, relata: "O que me motivou e chamou atenção para a criação do Núcleo foi a atitude das mulheres no ano de 2004, que se uniram para sair em defesa do clube que passava por um dos piores momentos da sua história".

Uma participante comentou que ficou sabendo da existência do núcleo através de uma amiga, e se interessou pelo fato de gostar de ver mulheres usando camiseta de futebol. Para algumas integrantes, que são aposentadas, o núcleo representa um trabalho, uma ocupação que possibilita estarem mais próximas do clube do coração. Tânia, 43 anos, lembrou:"Entrei no Núcleo com a única intenção de ter companhia para consumir o futebol, ter quem presentear com produtos futebolísticos e com quem discutir sobre o assunto. Mas, encontrei dentro deste grupo uma família".

No Quadro 1, faz-se uma análise dos principais resultados. 
Quadro 1 - Análise dos Dados (Análise de Conteúdo)

\begin{tabular}{|c|c|c|}
\hline CATEGORIAS & CÓDIGOS/ CRITÉRIOS & RESULTADOS \\
\hline & $\begin{array}{l}\text { Família } \\
\text { Gostos e Preferências } \\
\text { Consumo } \\
\text { Fanatismo } \\
\text { Preconceitos } \\
\text { Participação Econômica } \\
\text { Presença nos Estádios } \\
\text { Humor } \\
\text { Paixão clubística } \\
\text { Núcleo de Mulheres Gremistas }\end{array}$ & $\begin{array}{l}\text { 1. Alteração de Humor: nas vitórias e } \\
\text { nas derrotas; } 2 \text {. Amor pelo Clube: } \\
\text { acima do amor pelo futebol; } 3 \text {. O NMG: } \\
\text { tem alta representatividade e } \\
\text { significância na vida das integrantes }\end{array}$ \\
\hline
\end{tabular}

Fonte: A autora, 2016.

\section{CONCLUSÃO}

Com o desenvolvimento deste artigo, foi possível conhecer a opinião dos autores em relação ao papel da mulher na sociedade, como ela se comporta e quais as suas atitudes diante da paixão pelo futebol. E, também analisar as implicações do Marketing e o comportamento quanto ao consumo feminino de produtos esportivos, além das influências exercidas pelo meio.

Diante de todos os indícios fornecidos através do Grupo Focal, ficou evidente que cada vez mais as mulheres estão buscando os seus espaços e fazendo valer os seus gostos e as suas preferências. Aquele ambiente hostil e machista do futebol está amenizado. O espaço é ocupado por um público mais delicado e elegante, que faz das arquibancadas dos estádios um lugar de integração, divertimento e passeio familiar. No entanto, essa diferença de público não deixa nada a desejar quando se trata de fanatismo e amor pelo clube. As torcedoras discutem e entendem de futebol tanto quanto os homens, buscam e lutam pela igualdade até mesmo na política do clube e nas suas representatividades.

Durante a discussão realizada no Grupo Focal, a influência familiar foi o fator mais preponderante para definir e aguçar o gosto pelo futebol das participantes. A maioria delas citou a família como a responsável pela condição hoje existente. Ao longo do estudo foi diagnosticado que o fanatismo é um 
ponto alto que acompanha as integrantes. Esse fenômeno possibilita o lazer, a interação entre elas e criação de um grupo de amigas. Essa paixão pelo futebol muitas vezes resulta em acontecimentos inusitados no cotidiano. Fatores psicológicos como alteração do humor, raiva e euforia igualmente fazem parte deste cenário.

Os resultados encontrados na discussão evidenciam que ainda existem barreiras e preconceitos por serem mulheres torcedoras de futebol. E isso acaba refletindo na participação delas na política dos clubes brasileiros. Um exemplo disso é a composição do conselho deliberativo dos clubes onde, em média, cada time possui 300 conselheiros, e o número de mulheres gira em torno de 10 a 20, ou seja, nem $10 \%$ de representatividade.

Mesmo que os clubes brasileiros deixam a desejar no quesito de ações de marketing para prospectar, fidelizar e atrair o público feminino, o ato de consumo e utilização dos produtos relacionados ao time de futebol é um hábito muito difundido entre elas. Tratando-se de um lugar que é conhecido como o país do futebol, torna-se necessário questionar o que ainda falta para que essas ações sejam desenvolvidas pelos clubes brasileiros de futebol. Pois, ficou evidente durante esse estudo que as mulheres também tem sido responsáveis pelo aumento de consumo do produto futebol.

Este estudo apresenta como limitação a amostra selecionada. Tendo em vista que foi realizado um Grupo Focal apenas com integrantes do Núcleo de Mulheres Gremistas, não é possível generalizar os resultados obtidos para todas as mulheres torcedoras de futebol. Outro fator limitador para a seleção dessa amostra foi o pouco ou quase nulo acesso às informações internas dos principais clubes brasileiros de futebol.

Por fim, para responder de forma resumida a questão de pesquisa proposta por esse estudo, foram observados como os principais fatores que levam as integrantes do Núcleo de Mulheres Gremistas a consumir o futebol: (a) família; (b)fanatismo; (c) paixão clubística; (d) gosto pelo esporte. E a paixão, emoção e Grêmio foram as motivações que ocasionaram a inclusão do público feminino no futebol. Sendo assim, sugere-se para futuros trabalhos uma maior abrangência de amostra e clubes de futebol ou grupos de torcedoras.

\section{REFERÊNCIAS}

BARDIN, Laurence. Análise de Conteúdo. Lisboa: Edições 70, 2009.

BARLLETA, M. Como as Mulheres Compram: Marketing para Impactar e Seduzir o Maior Segmento de Mercado. Rio de Janeiro: Campus, 2003.

BLACKWELL, Roger D.; MINIARD, Paul W.; ENGEL, James F.Comportamento do

Consumidor. São Paulo: Cengage Learning, 2011. 
CAMPOS, Priscilla A.;SILVA, Silvio R. Mulheres e o lazer esportivo no campos de futebol. Anais do XVI Congresso Brasileiro de Ciências do Esporte e III Congresso Internacional de Ciências do Esporte, Salvador: 2009.

CARDIA, Wesley. Marketing Esportivo e Administração de Arenas. São Paulo:Atlas, 2014.

CARVALHO, Beto. Entrevista com o CEO de Marketing do GrêmioFoot-Ball Porto Alegrense. Porto Alegre, 2016.

COSTA, Leda M. O que é uma torcedora? Notas sobre a representação e autorepresentação do público feminino no futebol. Rio de Janeiro: Esporte e Sociedade, 2007.

CUPINI, Flávia Fernandes Silveira; BERNARDI, Flávia Camargo; BONASSINA, Daniela; BIEGELMEYER, Silvana Cargnino; BIEGELMEYER,Uiliam Hahn; CAMARGO, Maria Emília; GALELLI, Ademar; MOTTA, Martha Elisete Ventura. Female Leadership: a Case Study in Cosmetics Company. International Journal of Current Research, v.9,p.57331-57339,2017.

DIAS, João G. F.; COSTA, Yata Anderson. Marketing Esportivo como ferramenta de sucesso das estratégias de Marketing nas Empresas. Lins, 2009.

DUBOIS, B. Compreender o consumidor. 2.ed. Lisboa: Dom Quixote, 1998.

DUNNING, Erik. O desporto como uma área masculina reservada. Lisboa: Difusão Editorial, 1992.

ESPARTEL, Lelis B. Atributos de Produto e Motivações de Compra no Mercado Jornalístico do Rio Grande do Sul. 1999, Dissertação (Mestrado em Administração) Universidade Federal do Rio Grande do Sul - UFRGS, Porto Alegre, 1999, 125 p.

FELICIO, Juliana R. Marketing Esportivo e a Mulher Torcedora. Brasília, 2009.

FLICK, Uwe. Introdução à Pesquisa Qualitativa. 3.ed. Porto Alegre: Artmed, 2008.

FUJISAWA, Marie S. Das Amélias as mulheres multifuncionais - A emancipação feminina e os comerciais de televisão. São Paulo: Summus Editorial, 2006.

GARCIA, Sheila F.; GONZALES, Sara; MAUAD, Talita. Análise do Comportamento de Compra de 3 segmentos de consumidores no Supermercado.REMark - Revista Brasileira de Marketing, São Paulo, v. 9, n. 1, p 17-39, jan./abr. 2010.

GIGLIO, Ernesto. O comportamento do Consumidor e Gerência de Marketing. São Paulo: Pioneira, 1996.

GIOIA, Ricardo; CROCCO, Luciano; TELLES, Renato; ROCHA, Telma; STREHLAU, Vivian. Fundamentos de Marketing - conceitos básicos. São Paulo: Saraiva, 2006. 
GOELLNE, Silvana V. Mulheres e o Futebol. Entre bolas e bonecas, a dificuldade de inserção. Disponível em: < http://pre.univesp.br/mulheres-e-futebol\#.

V1xLXbsrKM8>. Acesso em: 14 de maio. 2016.

IBGE. Instituto Brasileiro de Geografia e Estatísticas. Disponível em: <http:/ /www. ibge.gov.br/home/>. Acesso em: 16 abr. 2016.

KARSAKLIAN, Elaine. Comportamento do Consumidor. 2. ed. São Paulo: Atlas, 2011.

KOTLER, Philip; KELLER, Kevin L. Administraçãode Marketing.12. ed. São Paulo: Pearson Prentice Hall, 2006.

KOTLER, Philip; ARMSTRONG, Gary.PrincípiosdeMarketing.São Paulo: Pearson Prentice Hall, 2007.

LIMEIRA, Tania Maria V.Comportamento do Consumidor Brasileiro.São Paulo: Saraiva, 2008.

MALHOTRA,Naresh.Pesquisa de Marketing: uma orientação aplicada.4. ed. Porto Alegre: Bookman, 2006.

MARCONI, Marina de A.; LAKATOS, Eva M. Técnicas de Pesquisa. 5. Ed. São Paulo: Atlas, 2002.

MARTINS,Andria; FRANCO,Haifa; ISABEL, Vitoria; NOVAES, Thalita.O papel da mulher no mercado brasileiro, 2015.

MATTAR, Fauze N. Pesquisa de Marketing - Ed compacta.SãoPaulo: Campus, 2012.

MCDANIEL, Carl D; GATES, Roger. Pesquisa de Marketing. São Paulo: Pioneira Thomson Learning, 2003.

MORGAN, M.; SUMMERS, J. MarketingEsportivo.São Paulo: Thomson Learning, 2008.

NMG. Núcleo de Mulheres Gremistas. Disponível em: <http:/ /www. mulheresgremistas.com.br/home/>. Acesso em: 15. Jun.2016.

OLIVEIRA,Louziane.Marketing Esportivo a Relação entre patrocinadores e os clubes de futebol. Disponível em:<http://www.administradores.com.br/artigos/ tecnologia/marketing-esportivo-a-relacao-entre-patrocinadores-e-os-clubes-defutebol/59254/>. Acesso em: 20 abr. 2016.

PEREIRA, Rodrigo P.A desigualdade dos gêneros, o declínio do patriarcalismo e as discriminações positivas "apud" Repensando o Direito de Família. Florianópolis, 2006. 
PITTS, Brenda G; STOTLAR, David K. Fundamentos de Marketing Esportivo. SãoPaulo:Phorte, 2002.

POPCORN, Faith; MARIGOLD, Lys. Público-alvo: Mulher - 8 verdades do Marketing para conquistar a consumidora do futuro.SãoPaulo: Campus, 2000.

PORTELA, Carmen B. Artigo: Marketing e o Comportamento do Consumidor. São Paulo, 2008.

REIN, Irving; KOTLER, Philip; SHIELDS, Ben.Marketing Esportivo: a reinvenção do esporte na busca de torcedores.PortoAlegre:Bookman, 2008.

ROCHA, A. CHRISTENSEN, C.Marketing, Teoria e prática no Brasil. 2. ed. São Paulo: Atlas, 1999.

SAMARA, Beatriz S.; MORSCH, Marco A.Comportamento do Consumidor Conceitos e Casos.São Paulo: PearsonPretinceHall, 2005.

SCHIFFMAN, L. G., \& KANUK, L.Comportamento do consumidor. 6. ed. Rio de Janeiro: LTC, 2000.

SECCO,Carlos Frederico C.; OLIVEIRA, Elda M.; AMORIM, Rafael M.Comportamento do Consumidor: Fatores que determinam o processo de compra no Mercado varejista em Palmas - TO.Revista Científica do ITPAC, Araguaína, v. 7, n. 3, pub. 4 jul. 2014.

SHANK, Matthew D.SportsMarketing: a strategic perspective. 2. ed. New Jersey: Prentice Hall, 2002.

SIQUEIRA, Marco Antônio.Marketing Esportivo: Uma visão estratégica e atual. SãoPaulo:Saraiva, 2014.

SOLOMON, Michael R.Comportamento do Consumidor. Porto Alegre: Bookman, 2011.

SOMOGGI, Amir. O futebol brasileiro precisa olhar para as mulheres. Disponível em: <http:/ / blogdojuca.uol.com.br/2016/02/o-futebol-brasileiro-precisa-olhar-paraa-mulher/>.Acesso em: 21 abr. 2016.

UNDERHILL, P. Vamos às compras: A Ciência do Consumo. 12. ed. Rio de janeiro: Campus, 1999.

VAVRA, T. G. Marketing de relacionamento. São Paulo: Atlas, 1993.

ZENONE, Luis Claudio. Marketing Futebol Clube. São Paulo: Atlas, 2014. 